\title{
INFLUENCE OF GENDER AND LEARNED HELPLESSNESS ON SOME MATHEMATICS-RELATED AFFECTIVE BEHAVIOUR OF LESOTHO SENIOR SECONDARY SCHOOL STUDENTS
}

\author{
H. J. NENTY AND E. N. OGWU
}

\begin{abstract}
Given that mathematics is the core subject for the development of science and technology, the problem of poor and deteriorating performance in the subject among African children demands more effort by researchers than is currently the case. Several factors combine to adversely influence mathematics-related affective behaviour of and hence the performance by students in the subject. This study examines the hypotheses that gender and level of learned helplessness (LLH) significantly influences such behaviour among senior secondary school students in the Kingdom of Lesotho. Three hundred and ten students from 12 randomly selected senior secondary schools in Lesotho completed questionnaires assessing their LLH in mathematics and some other mathematics-related affective variables. Data analysis using two-way ANOVA indicated that gender and the LLH in mathematics significantly influences students' attitude towards mathematics. Students with high LLH showed poor attitude towards mathematics, attach less value to mathematics and have high tendency to cheat in mathematics exam. However, students with low LLH showed more positive attitude and value towards mathematics and a low tendency to cheat during mathematics examination. These findings were discussed and recommendations were made.
\end{abstract}

KEYWORDS: Gender; learned helplessness; attitude towards mathematics; value attached to mathematics.

\section{INTRODUCTION}

The application of mathematics in science and technology gives it a prime of place among related subjects in secondary schools. But, occasionally we come across students who are hardened in their decision not to learn mathematics because all their previous efforts have not been fruitfully rewarded. Many affective ill feelings against the subject emanate from this experience of repeated failure. These include unfavorable attitude, poor value attached to the subject, low class participation and tendency to cheat during a test or an examination in the subject. Since affective feeling towards a subject has a significant influenced on one's cognitive behaviour on that subject, these ill feelings towards mathematics tend to translate into poor performance in the subject (Yates, 2008). Learned helplessness as it is called, is a state of psychological frustration that results from one's experiences of failure at earlier attempts at or experiences with the same or related problem. A learner that has been psychologically "turned-off" by an experience on a particular task is said to have learned to be helpless given that task (Wikipedia, 2008).

When individuals become helpless, it is believed to be associated with depression, hopelessness, dejection and rejection. This, in turn is associated to three problems of motivation, cognitive and emotional in people (Madden, 2007). A lot of factors such as genetic, environmental set up, stress, emotions and feelings have been identified to be responsible for LLH (Caldarone, George, Zachariou \& Picciotto, 2000). Many students find learning easy while others find it difficult. Many are optimistic while some are pessimistic about learning at school. In research, literature is often taken for granted that there is a problem concerning gender, LLH and mathematics

E H. J. Nenty, Department of Educational Foundations, University of Botswana, Gaborone

E. N. Ogwu, Department of Educational Foundations, University of Botswana, Gaborone 
behaviour of students which this study tends to establish.

\subsection{Theoretical Background}

Researchers believe that LLH is a mental state in which people feel that they have no control over their failures and success on academic work (Peterson, Maier, \& Seligman, 1993; Sideridis, 2008). People who experience LLH struggle with three problems: motivational, cognitive and emotional (Fiske \& Taylor as cited in Madden, 2007). A depressed person thought about the bad event in more pessimistic ways than a non depressed person (Madden, 2007). Predictions from these will be used to solve various educational problems in the classroom situation. The stereotyped belief of mathematics as a male domain is nurtured from birth by various agents of socialization, which influence children behaviour at school (Nenty, 2005). This attitude is exhibited in most cultures in Africa which tailor male and females into different fields of study. Mathematics is popularly stereotyped as male subject and the society tends to look at a female who does mathematics as weird. Hence since all actions and activities are geared to uphold society's belief, effort by females to do mathematics tend to be frustrated and hence unlike the males they learn to be helpless than males in the subject.

Affective component measures the degree of emotions or feelings towards an attitude object, while cognitive components accounts for the beliefs about the characteristics of the attitude object (Subramaniam \& Silverman, 2007; Holfve-Sabel, 2006). This degree of emotional attraction and beliefs based on attitude determine the general feelings such as interest, liking/disliking of school subjects in the curriculum as well as its usefulness (Curry, 2007; Obanya, 2007; Reyes, 1984). A positive attitude toward mathematics is an important educational outcome (Reyes, 1984). It is believed that students who feel very positive about mathematics will achieve at a higher level than a student who has a negative attitude towards mathematics. Attitude influences students' level of class participation in a subject. Nevertheless, usefulness of mathematics is an important factor in determining whether students will elect or take mathematics class or desire for mathematics related career. Students vary on how they view mathematics both for their current needs and for the future (Reyes, 1984).
Cheating during examination is strongly suspected to relate to LLH. This behaviour includes: using crib notes, on an examination, copying answers from another student's paper, letting others copy a test, examination or homework paper, plagiarizing and ghost writing (Nenty, 1988; Bushway \& Nash, 1977). It is believed that students cheat due to desperation and pressure to attain high grades, to achieve scholarships, pressure from parents, society, friends, peers, and from professors (Summary of Comments, 2008; Nenty, 2001). Alternate forms of cheating observed were also identified as: stashing cheat notes in the washroom, writing on various body parts, hiding and using unauthorized cheat sheets in an exam, faking or altering an examination for additional marks, talking during an exam, conferring with others while handing in a test after time is called, using hand signals in an examination to allow others to copy from you, obtaining an unauthorized copy of examination questions beforehand, using unauthorized electronic aids (preprogrammed calculators, cell phone messaging, preprogrammed pocket translators) in an examination, writing answers on a desk, stealing a student's study material to sway bell curve, hacking or exploiting online quiz and examination systems, faking or actually inflicting damage to one's person to postpone taking an exam, probing an invigilator for specific answers, failing to document sources of ideas, buying papers from "hired" tutors, submitting a paper that was written for another course, falsifying lab or research data (Summary of Comments, 2008).

\subsection{The Problem and Purpose of the Study}

Over the years, performance of students in mathematics by students in Lesotho secondary schools seems relatively very poor at the classroom and school certificate levels. Experiences and knowledge of repeated failure across the years cause students to learn to be helpless in the subject. It puts students in a helpless and hopeless situation and this tends to influence several of their affective behaviour towards mathematics. In most cases, many factors are attributed to this predicament and this tends to lead to negative attitude towards and low value attached to mathematics, poor class participation and tendency to cheat in order to pass. Given that at their level of development, most students do not seem to understand the importance of the subject, this could have serious 
impact on students' choice of carrier and even every day practices if this problem is not rectified at the earliest time. The question is, among secondary school students in Lesotho, how does gender and LLH influence the affective behaviour of students in mathematics? The purpose of undertaking this study is to examine the influence of gender and LLH on senior school students' attitude towards and, value attached to mathematics, level of class participation and tendency to cheat during mathematics examinations. Expected findings will be significant to students, teachers, educational administration, policy makers, to literature, theory and practice. The research question is, to what extent does gender and the LLH influence students' affective behaviour in terms of attitude towards and value attached to mathematics as well as class participation and cheating tendency in mathematics examination?

\subsection{Research Hypotheses:}

The following null hypotheses were posited to guide the study in the search of solution to this problem.

$\mathrm{H}_{1}$. Gender and LLH have no significant influence on students' attitude towards mathematics.

$\mathrm{H}_{2}$. Gender and LLH have no significant influence on students' value attached to mathematics.

$\mathrm{H}_{3}$.Gender and LLH have no significant influence on students' level of participation during mathematics lesson.

$\mathrm{H}_{4}$ Gender and LLH have no significant influence on students' tendency to cheat during mathematics examination.

\section{LITERATURE REVIEW}

Research has shown that LLH influence students' affective and cognitive behaviour in mathematics. This, especially among female students, is reflected in their negative attitude towards mathematics (Gutbezahl, 2008; Hall, 2008; Ryckman \& Peckham, 2008). Contrary to this finding, Parsons and colleagues (2008) found out that differences between males' and females' performance in mathematics is quite small compared to the anti female stereotypes that many people hold. The result of the Third International Mathematics and Science Study (TIMSS), conducted in 1995 in 21 countries, revealed a significant gender differences in mathematics performance in favor of males in all but one of the countries examined (Keller, 2002; Meelissen \& Luyten, 2008). These differences are actually attributed to learned-helplessness pattern. However, Nenty (2008) found that mathematics-related behaviour is transmitted in the culture through several processes of socialization, which influences students' attitude towards mathematics. Rech (2008) also reported that poor performances in mathematics was caused by LLH, negative attitude, low intelligence, anxiety and the inability to see the usefulness of mathematics in life. Rech contended that girls who have little faith in their own ability tend to attribute success in mathematics class to external causes, such as luck, or to situational causes, such as effort. However, Watts (2008) found out some contextual reflections about girls which have influenced their gender and affective disposition in mathematics class, such as:

- Girls' status is consistently lower than that of males

- $\quad$ Teachers may stereotype girls as neat, hardworking and good at computation, but not as imaginative and mathematically insightful as boys;

- $\quad$ Girls have a more negative attitude than boys toward learning advanced mathematics;

- Females lack the ability of males; Females lack confidence in learning mathematics and consequently suffer anxiety concerning mathematics;

- $\quad$ Females attribute their own success to external factors;

- $\quad$ Females do not believe mathematics to be useful;

- Mathematics is stereotyped as a male domain.

These are likely to influence students' participation in mathematics classroom as well as cheating tendency which literature has not focused on so far.

From the review of related literature gathered, gender and LLH was more focused on gender differences in mathematics and its attribution. It has been a controversy that when it comes to mathematics LLH is more common among females than among males and that it is through its influence that females tend to underperform in mathematics. These occurrences were attributed to high anxiety, lack of confidence and pessimistic believe that they 
cannot perform well in mathematics since it is a domain for men. Very little has been researched on the influence of gender and LLH on some affective behaviour of students in relation to attitude, values attached to mathematics, class participation and tendency to cheat in the exam. This study therefore wishes to contribute to the filling of such gap and hence to bring added knowledge to literature.

\section{RESEARCH DESIGN AND METHODOLOGY}

This is a quantitative study with a survey inferential design carried out using a random sampling of 12 senior secondary schools in Lesotho. The sample was thus composed of 310 students. Out of 380 questionnaires administered to the students, that were randomly selected, 310 $(82 \%)$ were returned. The questionnaire which was face validated has 20 closed response items designed to measure the variables of LLH in mathematics, students' attitude, values, class participation and tendency to cheat in mathematics exam. Positive affectivity were assessed using adjectives such as alert, attentive, determined, interested, active, enthusiastic, excited, inspired, proud, and strong; while negative affectivity were assessed using the adjectives: hostile, irritable, upset, afraid ashamed, distressed, guilty, jittery, nervous and scared. The questionnaire consisted of two sections (A\&B); Section A demanded respondents' demographic information such as age, gender and school while Section B consisted of responses on their affective behaviour towards mathematics. These consisted of attitude towards mathematics (7 items), the level to which value is attached to mathematics (4 items), level of participation during mathematics lesson (4 items), and level of tendency to cheat during test or examination in mathematics (2 items). Students were classified into 3 (high, average \& low) levels LH in mathematics based on their responses to items designed to measure this variable. A five-option Likert-type responses consisting of strongly disagree, disagree, tend to agree, agree, and strongly agree was used to elicit information from the respondents on each of these variables. The instrument was face-validated by submitting it for scrutiny and comments to two graduate students and one lecturer all in the area of tests and measurement. Cronbach alpha reliability estimates analyses for these variables gave .883 for attitude towards mathematics, .612 for learned helplessness, .724 for level of value attached to mathematics, .788 for level of participation during mathematics lesson, and a split-half analysis corrected for test length gave an estimate of .654 for tendency to cheat during mathematics tests or examination. To test the hypotheses, data were analyzed using two-way ANOVA in SPSS version 15 package.

\section{ANALYSIS OF DATA AND INTERPRETATION OF RESULTS}

\section{$H_{01}$. Gender and the level of LLH have no significant influence on students' attitude towards}

mathematics.

This hypothesis was tested by analyzing the relevant data through two-way ANOVA to establish the influence of gender and levels (low, average, high) of LH on students' attitude towards mathematics (see Table 1). The associated test resulted in $F(1,284)=16.207$, $p<.05$ for gender and $F(2,284)=76.940, p<.05$ for LLH. Following these results, the null hypotheses that gender and level of LLH has no significant influence on students' attitude towards mathematics were rejected; hence, gender and LLH significantly influences students' attitude towards mathematics. As indicated in Table 1, male students showed a significantly higher mean attitude towards mathematics than female students. 
Table 1: Two-way ANOVA of the influence of Gender and LLH on Students' Attitude towards Mathematics

\begin{tabular}{|c|c|c|c|c|c|c|}
\hline \multirow[b]{2}{*}{ Gender } & \multirow[b]{2}{*}{ LLH } & \multicolumn{5}{|c|}{ Students' Attitude Towards Mathematics } \\
\hline & & & $\mathrm{n}$ & \multicolumn{2}{|c|}{ Mean } & Std. Dev \\
\hline \multirow{4}{*}{ Female } & \multicolumn{2}{|c|}{ Low } & 40 & \multirow{2}{*}{\multicolumn{2}{|c|}{$\begin{array}{l}28.90 \\
25.14\end{array}$}} & 2.83 \\
\hline & \multicolumn{2}{|c|}{ Average } & 44 & & & 4.79 \\
\hline & \multicolumn{2}{|c|}{ High } & 50 & \multicolumn{2}{|l|}{20.24} & \multirow{2}{*}{$\begin{array}{l}5.25 \\
5.72\end{array}$} \\
\hline & \multicolumn{2}{|c|}{ Total } & 134 & \multicolumn{2}{|l|}{24.43} & \\
\hline \multirow{4}{*}{ Male } & \multicolumn{2}{|c|}{ Low } & 62 & \multicolumn{2}{|l|}{28.48} & 2.76 \\
\hline & \multirow{2}{*}{\multicolumn{2}{|c|}{ Average }} & 52 & \multicolumn{2}{|l|}{27.21} & 3.76 \\
\hline & High & & 36 & \multicolumn{2}{|l|}{21.78} & 5.41 \\
\hline & \multicolumn{2}{|c|}{ Total } & 150 & \multicolumn{2}{|l|}{26.43} & 4.69 \\
\hline \multirow{4}{*}{ Total } & \multirow{2}{*}{\multicolumn{2}{|c|}{$\begin{array}{l}\text { Low } \\
\text { Average }\end{array}$}} & 102 & \multicolumn{2}{|l|}{28.65} & 2.78 \\
\hline & & & 96 & 26.26 & & 4.36 \\
\hline & \multicolumn{2}{|c|}{ High } & 86 & 20.88 & & 5.34 \\
\hline & Tot & & 284 & 25.49 & & 5.29 \\
\hline Source of $\mathrm{V}$ & ion & SS & dff & MS & $F$ & $p$ \\
\hline Gender & & 283.239 & 1 & 283.239 & 16.207 & .000 \\
\hline LLH & & 2689.171 & 2 & 1344.585 & 76.940 & .000 \\
\hline Gender*LLH & & 82.277 & 2 & 41.138 & 2.354 & .097 \\
\hline Error & & 4858.281 & 278 & 17.476 & & \\
\hline Total & & 7912.968 & 283 & & & \\
\hline
\end{tabular}

$\mathrm{R}$ Squared $=.386$

Post hoc follow-up analysis using the least significant difference (LSD) revealed that students with low LLH had significantly $(p<.05)$ higher mean attitude towards mathematics than those with either average or high LLH with the mean difference decreasing as the level of LLH increases. However, result further shows that there is no significant interaction effect of gender and LLH as far as students' attitude towards mathematics is concerned at Cambridge Overseas School Certificate (COSC) level of education in Lesotho. This shows that gender and LLH have independent significant influence on the attitude of secondary school students in Lesotho.

$H_{\text {o2. }}$ Gender and LLH have no significant influence on students' value attached to mathematics.
This hypothesis was tested by performing a two-way ANOVA to establish the influence of gender and levels (low, average, high) of LH on students' value attached to mathematics (see Table 2). The test on students' value attached to mathematics resulted in $F(1$, $301)=3.18, p>.05$, and for $\operatorname{LLH}, F(2,301)=$ $20.61, p<.05$. Following these results, the null hypothesis that gender has no significant influence on value attached to mathematics was retained, while the null hypothesis that the level of LLH has no significant influence on students' value attached to mathematics was rejected. Hence, gender does not significantly influence student's value attached to mathematics while LLH significantly influences students' value attached to mathematics. 
Table 2: Two-way ANOVA of the influence of Gender and LLH on Students' Value attached to Mathematics

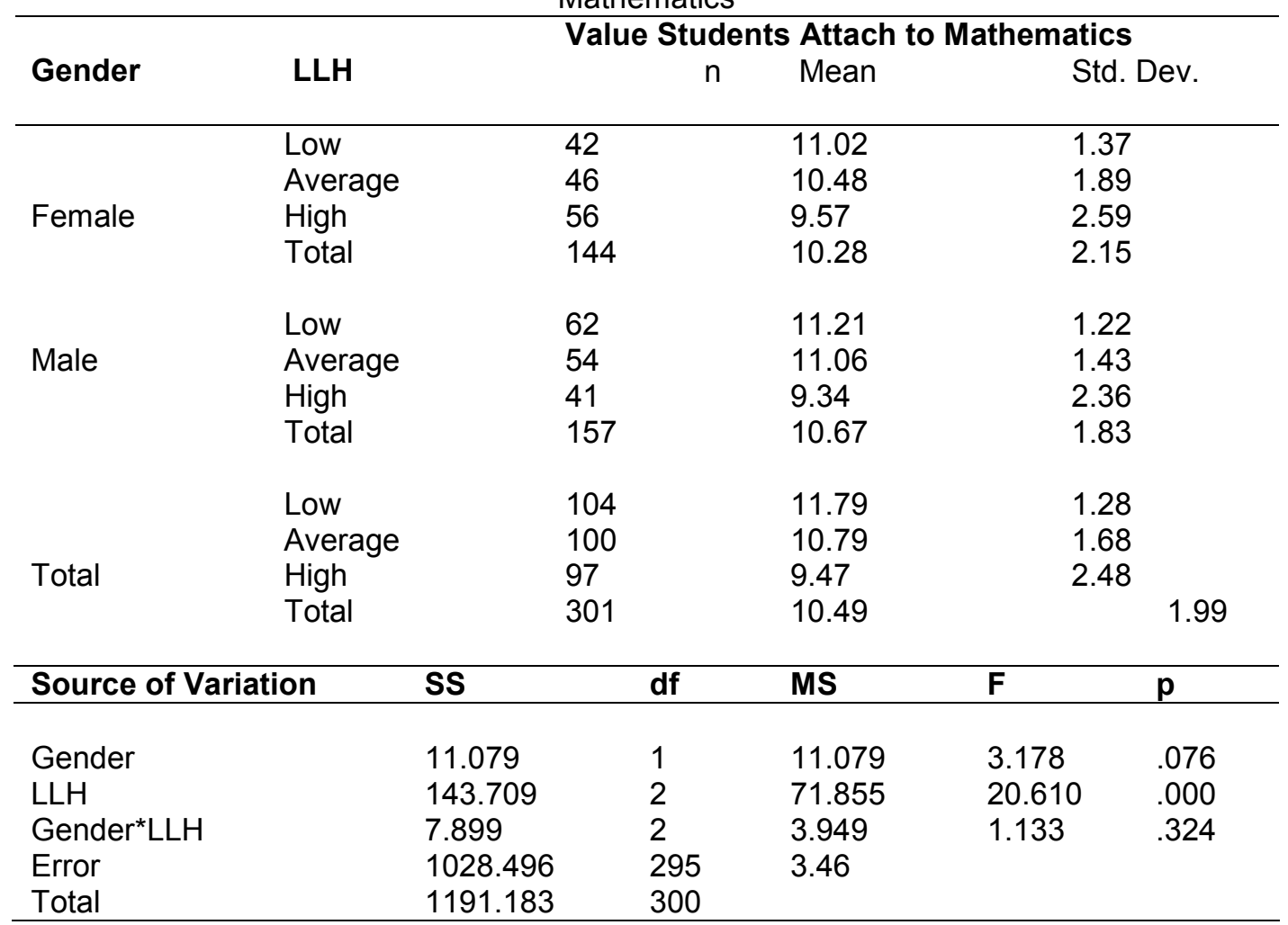

R-squared $=.137$

Post hoc follow-up analysis using the least significant difference (LSD) revealed that students with low LLH had significantly $(p<.05)$ higher mean value than those with either average or high LLH, with the mean difference decreasing as the LLH increases. Result reveals that students with low LLH attach higher value to mathematics than students with either average or high LLH.

The result further shows there is no significant interaction effect of gender and level of LLH on students' value attached to mathematics is concerned at Junior Certificate (JC) and COSC level of education in Lesotho. This shows that gender and LLH are independently influencing these behaviours. There is no attribution of one to the other.

$H_{03}$.Gender and LLH have no significant influence on students' level of participation during mathematics lesson.

This hypothesis was tested through twoway ANOVA of the variability of level of students' participation during mathematics lesson brought about by gender and levels (low, average, high) of LH on students.(see Table 3) The test by gender resulted in $F(1,310)=.50, p>.05$ and by LLH, $F(2,310)=2.01, p>.05$. following from these, the null hypothesis that gender 
Table 3: Two-way ANOVA of the influence of Gender and Level of LLH on Students' Level of participation in Mathematics Lesson

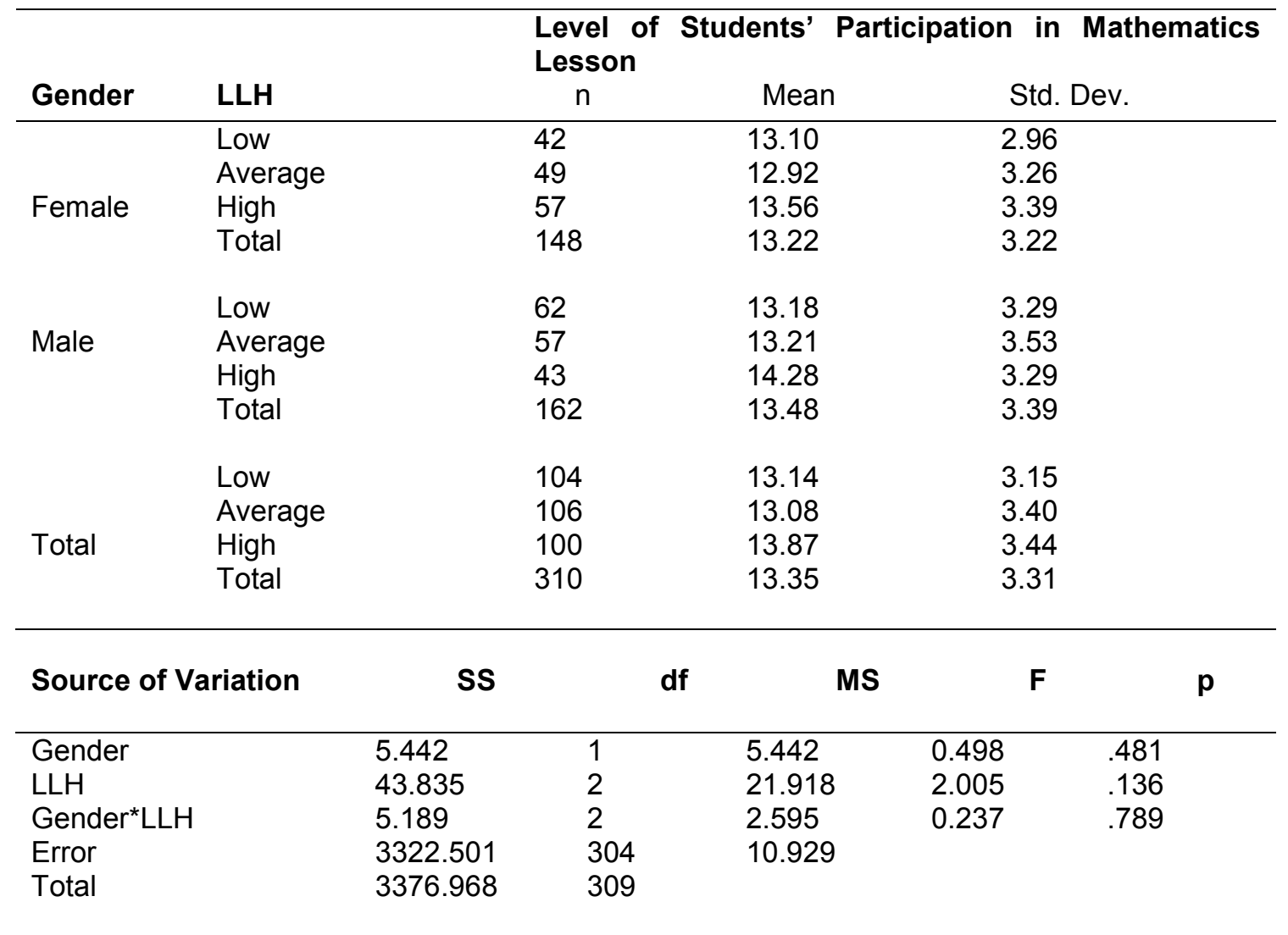

$$
\text { R Squared }=.016
$$

and level of LLH has no significant influence on students' level of participation during mathematics lesson was retained; gender and LLH does not significantly influence students' level of participation during mathematics lesson.

$H_{04}$ Gender and LLH have no significant influence on students' tendency to cheat during mathematics examination.

This hypothesis was tested by performing a two-way ANOVA to establish the influence of gender and levels (low, average, high) of LH on students' tendency to cheat during mathematics examination (see Table 4). The test by gender gave $F(1,301)=.22, P>.05$ and by LLH,
$\mathrm{F}(2,301)=19.85, \mathrm{P}<.05$. Following these results, the null hypothesis that gender has no significant influence on the tendency to cheat during mathematics examination is therefore retained; while the one that holds that the level of $\mathrm{LH}$ has no significant influence on the tendency to cheat during mathematics examination is therefore rejected. Hence among secondary school students in Lesotho, gender does not significantly influence students' tendency to cheat during mathematics examination but students' level of LLH significantly influences their tendency to cheat in mathematics examination. 
Table 4: Two-way ANOVA of the influence of Gender and LLH on Students' Tendency to Cheat during Mathematics Examination

\begin{tabular}{|c|c|c|c|c|c|}
\hline \multirow[b]{2}{*}{ Gender } & \multirow[b]{2}{*}{ LLH } & \multicolumn{4}{|c|}{$\begin{array}{l}\text { Students' Level of Tendency to Cheat During } \\
\text { Mathematics Examination }\end{array}$} \\
\hline & & $\mathrm{n}$ & \multicolumn{2}{|c|}{ Mean } & Std. Dev. \\
\hline & Low & 41 & 3.24 & & 1.84 \\
\hline & Average & 49 & 4.96 & & 2.56 \\
\hline Female & High & 52 & 5.48 & & 3.31 \\
\hline & Total & 142 & 4.65 & & 2.83 \\
\hline & Low & 60 & 3.75 & & 1.95 \\
\hline Male & Average & 56 & 4.68 & & 3.02 \\
\hline & High & 43 & 6.42 & & 2.94 \\
\hline & Total & 159 & 4.80 & & 2.83 \\
\hline & Low & 101 & 3.54 & & 1.91 \\
\hline & Average & 105 & 4.81 & & 2.80 \\
\hline Total & High & 95 & 5.91 & & 3.17 \\
\hline & Total & 301 & 4.73 & & 2.83 \\
\hline Source of Variation & SS & df & MS & $\mathbf{F}$ & $\mathbf{p}$ \\
\hline Gender & 1.551 & 1 & 1.551 & 0.218 & .641 \\
\hline LLH & 282.161 & 2 & 141.080 & 19.853 & .000 \\
\hline Gender*LLH & 19.101 & 2 & 9.551 & 1.344 & .262 \\
\hline Error & 2096.390 & 295 & 7.106 & & \\
\hline Total & 2399.203 & 300 & & & \\
\hline
\end{tabular}

R-squared $=.126$

Post hoc follow-up analysis using the least significant difference (LSD) revealed that students with high LLH had significantly $(p<.05)$ higher mean tendency to cheat mean than those with either average or low LLH, with the mean difference decreasing as LLH decreases. Similarly, students with low LLH have a significantly lower tendency to cheat while those with higher LLH have higher tendency to cheat in mathematics examination. The interaction between gender and level of LLH did not yield a significant influence on students' tendency to cheat during mathematics examination by secondary schools students in Lesotho.

\section{Summary, Discussions, Conclusion and Recommendations}

This study set out to consider for students in Lesotho secondary schools the influence of gender and LLH on some mathematics-related affective behaviour. Both gender and level of LLH were found to have significant influence students' attitude towards mathematics and non-significant influence on level of participation in mathematics classroom. Males were found to have a more favourable attitude towards mathematics than females and students with low LLH also had more favourable attitude towards mathematics than those with either average or high LLH. While a significant difference was observed in the value attached to mathematics and tendency to cheat during tests and examinations across levels of $\mathrm{LH}$, such difference was not observed across gender. Among secondary school students in Lesotho it was the higher the level of LLH, the lower the value attached to mathematics and the higher the tendency to cheat during tests and examination in the subject. For these students, neither level of LLH nor gender influenced any significant difference in the level of classroom participation during mathematics lesson. 
The tremendous adverse influence LLH has on mathematics performance is obvious here. According Nenty and Ogwu (in press), for secondary school students in Lesotho, it has a direct and significant influence on performance in mathematics and several studies have found attitude to have significant influence too on performance and in this study with the same population attitude has been found to be significantly influenced by LLH. Hence LLH has both a direct and an indirect adverse influence on performance in the subject. That is, besides underlying poor performance in mathematics by secondary school students in Lesotho, it also wrecks learners' attitude toward and hence performance in the subject. And also, the findings of this study add to the voice of several research studies that males display a significantly more favourable attitude towards mathematics than females. This, coupled with Rech (2008) and Watt's (2008) findings that LLH towards mathematics is higher among females than males argue strongly for the bias towards males of the influence gender on mathematics performance.

The finding that Lesotho females secondary school students, like their male counterparts realize equally the value of mathematics as a subject refutes Watts (2008) findings with pupil in USA, UK, Europe and Australia that generally females do not believe mathematics to be useful and hence tend not to pursue higher-level mathematics because of a perceived lack of relevancy to future needs. This might stem from ingrained stereotyping of some specific occupation as female fields, the availability of opportunity in such fields for ample choice by females, a situation of sensitive occupational differentiation that is not available in Lesotho. Learned helplessness is an explanatory style which gets more and more crystallized as years of unsuccessful experience with mathematics pass by and this tends to infect ones total affective feeling towards mathematics. Persisting cognitive feeling of helplessness towards mathematics by COSC level students tends to create an envelop of negative affective feeling towards the subject, hence the significantly poorer value attached to mathematics displayed by learners with high LLH. Some students enjoy learning and studying mathematics, whereas others do not because learned helpless people feel they have no control over success and failure on academic tasks which could influence students' perceived value attached towards mathematics.

It was observed that for Lesotho secondary school students, gender and LLH do not significantly influence students' level of participation during mathematics lesson. Both male and females equally take part in mathematics lesson irrespective of their LLH. This has added some knowledge to literature. Gender also was not found to significantly influence students' tendency to cheat in mathematics examination. However, students' LLH significantly influences their tendency to cheat in mathematics examination. Students with lower LLH have a lower tendency to cheat while those with higher LLH have higher tendency to cheat in mathematics examination. This could be attributed to a sense of powerlessness engendered by LLH due to the perception of lack of ability to bring about a change in their performance (Peterson, Maier, \& Seligman, 1993). Cheating during examination tends to be the last resort of a learned helpless individual to enhance his/her performance. Such performance is not undelied by learning, but by fear of failure and hence the determination to pass by all means.

Although, not much has been done at this educational level, more research is needed on affective behaviour of students towards mathematics. The impact of LLH needs to be researched. These studies have certain implications for teachers. Teachers are in a good position both to assess their students' attitude and how useful they view mathematics to be and give students information about the importance of studying mathematics. They are also in a position to assess their students' level class participation for classroom management applications, as well as their students' level of cheating during mathematics examination. Information emanating from these assessments informs the institution about the prevalence and implications of cheating in the school. Effective teacher preparation should be in place to enable qualified teachers handle mathematics using strategies that could motivate students with high LLH in mathematics irrespective of gender.

According to Seligman (1975), LLH is an explanatory style which can be replaced with "learned optimism." To combat or even prevent $\mathrm{LLH}$, he recommended that the teachers should use techniques which he has successfully used in cognitive therapy with persons suffering from depression. These include identifying negative 
interpretations of events, evaluating their accuracy, generating more accurate interpretations, and countering the tendency to imagine the worst possible consequences for an event. Children should be taught to dispute their own negative thoughts while promoting their problem-solving and social skills (Healthline, n.d.). He also instructed that parents, in order to promote learned optimism, should applaud and encourage their children to master new situations and let them have as much control as possible in everyday activities such as dressing and eating. In addition, parents should consciously influence the degree of optimism in their children through their own attitudes toward life and their explanatory styles, which should be consciously transmitted even to children at very young age (Healthline, n.d.).

Generally poor performance in and unfavourable affective feelings towards any subject are attributable to LLH, and these are common among students. The self help movement is based on the optimistic belief that we can change ourselves for the better. Predictions from these could be used to solve various educational problems in the classroom situation. Most poor performances in tests and examinations and classroom cheating could be consequences of LLH which influences ones emotions and attitude towards school subjects (Holfve-Sable, 2006).

\section{REFERENCE}

Bushway, A., and Nash, W., 1977. School cheating behavior. Review of Education Research, 47, 623- 632.

Caldarone, B.J., George, T. P., Zachariou, V., and Picciotto, M.R., 2000. Gender differences in LLH behavior are influenced by genetic background. Journal of Pharmacology Biochemistry and Behavior, 66 (4): 811817(7).

Curry, R. L., 2007. Subject preference of fifthgrade children. Peabody Journal of Education. Retrieved August 20, 2007 from

http://www.jstor.org/view/0161956/ap050 $241 / 05900070 / 0$

Gutbezahl, J., 2008. How negative expectancies and attitudes undermine females' mathematics confidence and performance. Retrieved March 7, 2008 from

http://www.inform.umd.edu/UMS+State/U MDProjects/MCTP/Essays/WomenAndM athematics.txt

Hall, R. D. G., 2008. An analysis of views of the nature of mathematics by gender. Retrieved June 3, 2008 from http://www.people.ex.ac.uk/PErnest/pom e16/docs/hall.pdf Healthline (n. d.). Learned helplessness. Retrieved February 10, 2009 from http://www.healthline.com/galecontent/le arned-helplessness

Holfve-Sabel, M., 2006. A comparison of student attitudes towards school, teachers and peers in Swedish comprehensive schools now and 35 years ago. Educational Research Journal, 48(1), 55-75.

Keller, J., 2002. Blatant stereotype threat and women's mathematics performance: Self-handicapping as a strategic means to cope with obtrusive negative performance expectations. A Journal of Research Retrieved June 3, 2008 from [http://www.questia.com/googleScholar.q st;jsessionid=LFTQ0JGyd0cjDc0RfnsNh 1hS7CQh9xyJ 2n6mBxv9LpQ5NQfyyDyg!1828415860 ?docld $=5000665990$

Madden, R., 2007. Learning helplessness. Retrieved June 16, 2007 from file://f.learning helplessness.htm.

Meelissen, M., and Luyten, H., 2008. The Dutch gender gap in mathematics: Small for achievement, substantial for beliefs and attitudes. Retrieved February 10, 2009 from http://www.sciencedirect.com/science?_o b=ArticleURL\&_udi=B6V9B-4SN8TXW-

$1 \&$ _user $=778200$ \&_rdoc $=1 \&$ fmt $=$ \&_orig $=$ search\&_sort $=d \& \overline{v i e w}=c \& \_$acct $=\mathrm{C} 0000$ 43160\&_version $=1 \&$ \&urlVersion $=0$ \&_use rid $=778 \overline{2} 00 \& \mathrm{md} 5=5 \overline{\mathrm{a}} 3 \mathrm{eb} 8614 \mathrm{baef} 279 \mathrm{f} 9$ $4 f e d 2 a 8 b 04781$

Nenty, H. J., 2008. Stereotype endorsement and mathematics-related behaviour among female secondary school students in the Kingdom of Lesotho. Gender \& 
Behaviour, 6(1), 1494-1518. Online: www.ajol.info/viewarticle.php?jid=139\&id $=42179$

Nenty, H. J., 2001. Tendency to cheat during mathematics examination and some achievement-related behaviour among secondary school students in Lesotho. IFE PsychologIA, 9(1), 2001, 47-64 On-line: http://www.oneworld.org/inasp/ajol/ifep/in dex.html

Nenty, H. J., 1988. Factors that influence students' tendency to cheat in examinations. Journal of Education in Developing Countries, 6, 70-78.

Nenty, H. J., and Ogwu, E. N., (in press). Influence of gender and learned helplessness on some mathematicsrelated cognitive behaviour of Lesotho senior secondary school students. IFE PsychologIA, 2009

Obanya, P., 2007. Curricular interest of a group of Nigeria secondary school students. The Journal of Negro Education, pp.298-302. Retrieved August 20, 2007 from

http://www.jstor.org/view/00222984/di990 429/99p0099f/0

Parsons, J.E., Meece, J. L., Adler, T.F. and Kaczala, C. M., 2008. Sex differences in attributions and LLH. Retrieved June 3, 2008

from http://www.springerlink.com/content/ b272uvwwwmv108v0/.

Peterson, C., Maier, S.E., and Seligman, M.E.P., 1993. LLH: A theory for the age of personal control. Retrieved September 17, 2007 from

http://www.iptforensics.com/journal/volu me6/j6_2_br9.htm.

Rech, J.F., 2008. A comparison of the mathematics attitudes of black students according to grade level, gender, and academic achievement. Journal of

Negro Education, The Spring, 1994.Retrieved June3, 2008 from http://findarticles.com/p/articles/mi_qa36 26/is_199404/ai_n8711136
Reyes, L.H., 1984. Affective variables and Mathematics Education. The Elementary School Journal, 84(5), 558581.

Ryckman, D.B., and Peckham, P., 2008. Gender differences in attributions for Success and failure situations across subject areas. Retrieved June 4, 2008 from [http://www.questia.com/googleScholar.q st;jsessionid=LG3JGJ2WtLGZ7ByLLZQ RRhLJ4Vb7bn0ZgQp6xwytg3FdGbKZ4z C1!13071843?docld=80924851

Seligman, M., 1975. Helplessness: On development, depression, and death. New York: W. H. Freemen

Sideridis, G. D., 2008. On the origin of helplessness behaviour of students with learning disabilities: avoidance motivation? Retrieved June 9, 2008

from

[http://www.sciencedirect.com/science? ob=ArticleURL\& udi=B6VDF-4DD6TF8D\&_user778200]

Subramaniam, P.R., \& Silverman, S. (2007). Middle school students' attitude towards physical education. Teaching and Teacher Education, 23(5), 602-611. Retrieved November 8, from [http;//www.sciencedirect.com/science?].

Summary of comments, 2008. Survey of SFU first-year Students on Perceptions of academic integrity in high School. Retrieved July 31, 2008 from http://www.sfu.ca/integritytaskforce/first $\%$ 20year\%20comments $\% 20$ summary $\%$ 20web.htm

Watts, J., 2008. Girls' nominal participation in mathematics: A preliminary investigation. Retrieved June 3, 2008 from: http://www.iier.org.au/qjer/qr11/watts.htm I

Wikipedia Free Encyclopedia, 2008. Learned helplessness. Retrieved June 3, 2008 from

http://en.wikipedia.org/w/index.php?title=| earned_helplessness\&action=edit 
Yates, S.M., 2008.Teacher perceptions, learned helplessness and mathematics achievement: A longitudinal study. Paper presented at the Australian Association for Research in Education Conference, Brisbane, 3 December, 1997. Retrieved February 22, 2008 from [http://www.aare.edu.au/97pap/yates256. htm]. 
